\title{
CONFLITOS, BARGANHAS E DESPREZO PELO INTERESSE PÚBLICO: ENQUADRAMENTOS DO CONGRESSO NACIONAL EM EDITORIAIS DA FOLHA DE S. PAULO
}

CONFLICT, BARGAIN AND DESPISE BY PUBLIC INTEREST: FRAMES OF THE CONGRESS IN FOLHA DE S. PAULO'S EDITORIALS

CONFLICTOS, NEGOCIACIONES Y DESPRECIO POR EL INTERÉS PÚBLICO: ENCUADRES DEL CONGRESO EN EDITORIALES DE FOLHA

Francisco Paulo Jamil Marques'

Camila Mont'Alverne ${ }^{2}$

Resumo: o objetivo do artigo é examinar os enquadramentos elaborados pela Folha de S Paulo em editoriais que tratam do Congresso Nacional, investigando-se as seguintes hipóteses: $\mathrm{H} 1$ : Os editoriais adotam um tom negativo em relação ao Congresso ao enquadrar o Legislativo e seus integrantes como atores recorrentemente envolvidos em barganhas, irregularidades e escândalos; H2: Ao tratar do Congresso em seus editoriais, a FSP procura construir sua própria imagem como defensora do interesse público. A Análise de Enquadramentos permitiu identificar os frames existentes em 40 editoriais publicados entre 2011 e 2013. Descobriu-se que o Congresso raramente é abordado de forma isolada, uma vez que os editoriais costumam evidenciar as relações que a referida instituição e seus agentes mantêm com outros poderes. Tais relações são caracterizadas pelos editoriais como conflitos e negociações prejudiciais ao interesse público. Ademais, o periódico

Doutor em Comunicação e Cultura Contemporâneas pela Universidade Federal da Bahia (UFBA). Professor da Universidade Federal do Paraná, UFPR, Curitiba, PR, Brasil. http://orcid.org/0000-0002-5256-1964. E-mail: marquesjamil@gmail.com

2 Doutoranda em Ciência Política, Universidade Federal do Paraná, UFPR, Curitiba, PR, Brasil. http://orcid. org/0000-0002-6100-4879.E-mail: camilapessoa31@gmail.com 
posiciona o Executivo como principal articulador do jogo político nacional, apesar de o Legislativo não ser necessariamente apresentado como um poder submisso.

Palavras-chave: Editoriais jornalísticos. Imagem pública. Congresso Nacional.

\begin{abstract}
Folha de S. Paulo (FSP) in order to verify the main frames emphasized by the newspaper when covering the Brazilian National Congress. Our hypotheses are: $\mathrm{H}_{1}$ : The editorials at stake adopt a negative tone towards Congress by framing the Legislature and its members as actors who are repeatedly involved in irregularities, and scandals; $\mathrm{H}_{2}$ : When addressing the Congress in its editorials, the newspaper seeks to build its own image as a watchdog. The article proposes a Frame Analysis to identify the frames in 40 editorials published between 2011 and 2013. Our results show that FSP act as a critical actor regarding the Brazilian House of Representatives and Senate: the relationships between the Executive and Legislative Branches are often characterized by the editorials as negotiations involving political agents with no commitment to public interest. Even if the Congress is not seen as a submissive Branch, the Brazilian Executive is characterized as the main organizer of the political game.
\end{abstract}

Keywords: Editorial journalism. Public image. Brazilian Congress.

Resumen: el objetivo del artículo es examinar los encuadres elaborados por el periódico Folha de S. Paulo en editoriales que abordan el Congreso Nacional Brasileño, investigando estas hipótesis: $\mathrm{H}_{1}$ ) Los editoriales adoptan un tono negativo, presentando el Legislativo y sus miembros como actores que constantemente participan de negociaciones, irregularidades y escándalos; $\mathrm{H} 2$ : Cuando encuadra el Congreso en sus editoriales, FSP intenta construir su propia imagen como defensor del interés público. Fue posible, con Frame análisis, identificar los encuadres existentes en 40 editoriales publicados entre 2011 y 2013. Los resultados indican que el Congreso raramente es presentado por separado de otras instituciones, una vez que los textos tienden a enfatizar sus relaciones con otros Poderes; estas relaciones son caracterizadas como conflictos y negociaciones perjudiciales al interés público; el periódico sitúa el Ejecutivo como el principal articulador del juego político nacional, a pesar de no presentar el Legislativo como un Poder necesariamente sumiso.

Palabras clave: Editoriales periodísticos. Imagen pública. Congreso Nacional Brasileño.

\title{
Introdução
}

Este trabalho se integra à agenda de investigações voltada a esclarecer em que medida as empresas jornalísticas cumprem um papel que vai além da sim- 
ples mediação entre a esfera civil e os agentes políticos - sobretudo quando se está tratando de textos editoriais, nos quais é possível verificar o esforço do Jornalismo para influenciar o leitor e, ao mesmo tempo, pressionar representantes e instituições do Estado. Assim, o objetivo do artigo é examinar um conjunto de editoriais publicados pela Folha de S. Paulo (FSP) - um dos jornais de referência do País - com o intuito de verificar quais são os principais enquadramentos enfatizados pelo referido periódico quando trata do Congresso Nacional.

Nesse contexto, propõem-se as seguintes perguntas de partida: Quais enquadramentos são acionados pela FSP em seus editoriais sobre o Congresso Nacional? Sabendo que o editorial é um espaço no qual o jornal configura sua própria imagem pública ${ }^{3}$ a imagem de outros agentes e instituições, que caracterizações a empresa privilegia nos referidos textos? Empiricamente, propõe-se um estudo que, por meio da Análise de Enquadramentos, adota como corpus 40 textos publicados entre 2011 e 2013 pela FSP que citaram as palavras-chave Congresso, Câmara e Senado.

É importante sublinhar duas justificativas concernentes à escolha do objeto de pesquisa: primeiramente, os editoriais mantêm relevância junto à audiência por colaborarem no processo de construção do contrato de leitura mantido entre a empresa jornalística e o público (BENETTI, 2006; HALLOCK, 2007); em segundo lugar, observe-se a importância do Congresso como espaço de discussão de regramentos que exercem impacto sobre a vida social, o que motiva a escolha de tal instituição como foco do artigo ora proposto (FIGUEIREDO; LIMONGI, 2001; AVRITZER; ANASTASIA, 2006; NICOLAU; POWER, 2007; POWER; ZUCCO JR., 2011). Assim, defende-se que a percepção acerca do desempenho de instituições como a Câmara dos Deputados e o Senado Federal, bem como sobre a performance de seus integrantes, está ligada, também, à cobertura opinativa (WEBER, 2004).

$O$ artigo está dividido em quatro partes: inicialmente, discute-se a literatura dedicada a abordar a política nos editoriais jornalísticos; em segundo lugar, são explanados os procedimentos metodológicos; posteriormente, os enquadramentos editoriais da FSP são apresentados e analisados, evidenciando-se o posicionamento e as caracterizações construídas pelo jornal em questão; por último, o artigo coteja os achados da investigação com a literatura pertinente da área.

3 Define-se imagem pública como "[...] um complexo de informações, noções, conceitos, partilhado por uma coletividade qualquer, e que o caracterizam. Imagens públicas são concepções caracterizadoras" (GOMES, 2004, p. 254). 


\section{A política nos editoriais jornalísticos: entre a cobertura negativa e a reivindicação de representante do leitor}

A partir do momento em que o Jornalismo passou a cobrir a área de política seguindo uma lógica própria, os agentes representativos perceberam que não mais poderiam controlar detalhes da cobertura (STRÖMBÄCK; VAN AELST, 2013; VAN DALEN, 2015). Com isso, o Jornalismo também garante espaço na configuração do jogo político. Em relação ao Legislativo, por sua vez, a literatura aponta que a cobertura sobre tal Poder tende a enfatizar características negativas ou pitorescas de seus integrantes, em detrimento da abordagem de questões substanciais (MANN; ORNSTEIN, 1994; ROZELL, 1994; JORGE, 2003; ARNOLD, 2004; AZEVEDO; CHAIA, 2008).

Ao mesmo tempo, cientes da importância da visibilidade para emplacar as agendas que lhes interessam, os agentes do campo político têm utilizado artifícios variados com o intuito de alcançarem espaço nos noticiários - seja ao adequarem a extensão de suas declarações ao que exige uma sonora telejornalística, seja ao produzir eventos que servem para chamar a atenção da mídia (GOMES, 2004; COOK, 2005). É verdade que dominar a gramática do campo jornalístico não garante que pautas ou enquadramentos sejam emplacados, mas atender aos chamados critérios de noticiabilidade tende a aumentar as chances de que isso aconteça (COOK, 1989; RODRIGUES, 1997; COOK, 2005; STRÖMBÄCK; NORD, 2006; SELLERS, 2009).

No caso específico dos editoriais jornalísticos (e da contribuição de tais peças para a formação de imagens públicas políticas), pode-se dizer que eles ocupam uma função singular ao elucidarem a posição institucional do periódico, apresentando-se como uma espécie de conselheiro do leitor (BELTRÃO, 1980; ARMAÑANZAS; NOCÍ, 1996; EILDERS, 1999; RUPAR, 2007). Destaque-se, entretanto, que o texto editorial constitui um paradoxo para a empresa jornalística: ao mesmo tempo em que é um espaço legítimo para veicular a opinião do jornal, acaba estabelecendo uma tensão permanente, já que os periódicos procuram se apresentar, nas seções noticiosas, como obedientes aos princípios da neutralidade e da objetividade (BARROS FILHO, 1995; CHRISTOFOLETTI; LAUX, 2008; GUAZINA, 2011; LISBOA, 2012).

Cientes disso, os responsáveis pelos editoriais apoiam-se na busca por um discurso de verdade a fim de fundamentar suas posições (PINTO, 2006; MORAES, 2007). Ressalte-se que as características do editorial podem variar a depender do papel e da importância atribuídos pelas empresas ao texto. Por exemplo, a FSP, periódico que será examinado na parte empírica deste trabalho, definiu o editorial da seguinte forma: 
Texto que expressa a opinião de um jornal. Na Folha, seu estilo deve ser ao mesmo tempo enfático e equilibrado. Deve evitar a ironia exagerada, a interrogação e a exclamação. Deve apresentar com concisão a questão de que vai tratar, desenvolver os argumentos que o jornal defende, refutar as opiniões opostas e concluir condensando a posição adotada pela Folha [...] (FOLHA DE S. PAULO, 2015).

A partir das questões de pesquisa apresentadas e da literatura examinada, as hipóteses do trabalho são as seguintes:

$\mathrm{H} 1$ : Os editoriais adotam um tom negativo em relação ao Congresso ao enquadrar o Legislativo e seus integrantes como atores recorrentemente envolvidos em barganhas, irregularidades e escândalos.

$\mathrm{H}_{2}$ : Ao tratar do Congresso em seus editoriais, a FSP procura construir sua própria imagem como defensora do interesse público.

É necessário ressaltar, a este ponto, que as hipóteses não são excludentes entre si. Na realidade, elas atuam de forma complementar, ao prospectar descobertas distintas que permitem alcançar os objetivos da investigação.

\section{Estratégias metodológicas}

Os estudos sobre enquadramentos midiáticos têm se mostrado relevantes e numerosos, a ponto de haver interesse da literatura em esclarecer certas confusões estabelecidas quanto aos modos de compreender conceitualmente - e apreender empiricamente - os chamados frames (SCHEUFELE, 2000; DE VREESE, 2005; MENDONÇA; SIMÕES, 2012; MIOLA 2012; POZOBON; SCHAEFER, 2014).

A perspectiva aqui privilegiada ressalta que os enquadramentos têm o papel de reduzir a complexidade dos assuntos abordados pela cobertura jornalística. Além disso, eles "também servem como atalhos interpretativos para membros da audiência, orientando-os a fazer atribuições de responsabilidade ou outros julgamentos" (KIM; SCHEUFELE; SHANAHAN, 2002, p. 8).

Saber transformar os acontecimentos em frames atraentes ao campo jornalístico faz parte do leque de estratégias utilizado por assessores de comunicação a fim de garantir maior controle sobre as mensagens emitidas para a audiência (JAMIESON; WALDMAN, 2003; ENTMAN, 2004; COOK, 2005; HANGGLI, 2012). Verifica-se, então, a existência de enquadramentos distintos em disputa na esfera de visibilidade pública, embora nem todos contem com o mesmo grau de acesso a produtos jornalísticos, uma vez que os periódicos também formulam seus próprios frames. 
As interpretações providas pelos editoriais acabam por salientar determinadas visões de mundo e, consequentemente, desejam orientar a maneira de o leitor enxergar a realidade construída, tornando factível a associação de tais textos com a ideia de enquadramento. Assim, embora parte das pesquisas usualmente aplique a análise de enquadramentos ao estudar textos de caráter informativo, defende-se que o editorial é um gênero no qual os frames também são adotados a fim de sustentar a opinião do periódico (ESSARY, 2007). Examinar os enquadramentos dos editoriais permite, em suma, estudar a natureza dos enquadramentos formulados pelas empresas e colocados em disputa na esfera de visibilidade pública.

É verdade que existem diferentes alternativas metodológicas dedicadas a compreender o posicionamento político de materiais jornalísticos. É o caso dos estudos sobre valência, que, ao longo dos últimos anos, desempenharam papel de destaque na área de Comunicação e Política no Brasil (ALDÉ; MENDES; FIGUEIREDO, 2007; CERVI; MASSUCHIN, 2013; FERES JÚNIOR; SASSARA, 2016). Porém, considera-se que a investigação dos frames pode trazer vantagens ao possibilitar, por exemplo, compreender os atributos e as perspectivas mobilizadas pelos jornais ao tratar do Congresso Nacional em seus editoriais. A análise de enquadramentos confere a oportunidade de estudar como e o que se fala sobre o objeto analisado, revelando-se adequada a uma pesquisa cuja preocupação privilegia os modos de construção da imagem pública do Poder Legislativo Federal.

\section{Sobre o corpus empírico e a operacionalização da análise}

A pesquisa se debruça sobre um conjunto de editoriais da Folha de S. Paulo, um jornal de referência (MIGUEL; COUTINHO, 2007) com tiragem entre as mais altas do Brasil (Associação Nacional de Jornais, 2017). Dentre as razões que merecem ser mencionadas para justificar a ênfase na FSP, está a autodefesa, elaborada pelo jornal, de que seria uma instituição apartidária (FOLHA DE S. PAULO, 2017a). Ao promover transformações internas em seu processo produtivo ao longo das últimas décadas, a Folha reivindica privilegiar o que ela denomina de "mandato do leitor" (ALBUQUERQUE; HOLZBACH, 2008; PINTO, 2012; AZEVEDO, 2016; FOLHA DE S. PAULO, 2017b).

Registre-se que a Folha de S. Paulo traz dois editoriais, diariamente, na página A2. Todos os textos investigados no presente trabalho foram publicados na versão impressa do jornal e acessados por meio do acervo disponível no portal da FSP. Foram selecionados apenas (a) editoriais que trouxessem, pelo menos, um dos 
seguintes termos: Congresso, Câmara ou Senado4; e (b) editoriais publicados entre 2011 e 2013, sendo considerados meses alternados (um semestre composto, a fim de aumentar a representatividade) e fora de períodos eleitorais. A escolha temporal é justificada por duas razões: o tratamento de textos do período eleitoral exigiria a discussão de uma literatura adicional sobre mídia e eleições; as atividades do Congresso - e, consequentemente, a cobertura editorial - sofrem alterações por conta da disputa pelo voto, o que poderia enviesar o estudo e impossibilitar que se investigasse apropriadamente a cobertura cotidiana. Em janeiro e fevereiro de 2011, seis editoriais atenderam às exigências do recorte e passaram a integrar o corpus. Em março e abril de 2012, são 24 textos, enquanto em maio e junho de 2013 a busca apontou a existência de mais 10 peças. $O$ total é de 40 peças analisadas.

Uma vez que o texto editorial é a unidade básica de análise, as estratégias apresentadas por Matthes e Kohring (2008) foram fundamentais para desenvolver uma proposta metodológica condizente com os objetivos e as hipóteses. Esses dois autores, a partir da definição de Entman (1993), apontam quatro elementos a integrarem um enquadramento: 1) a definição de um problema: consiste na definição de uma questão ou na atuação de agentes relevantes que discutem certo problema; 2) uma interpretação causal: o diagnóstico de falha ou de sucesso em relação a medidas específicas; 3) uma avaliação moral, que pode ser positiva, negativa ou neutra e referir-se a diferentes objetos; e 4) a recomendação de uma solução para o problema 5 . A definição de tais elementos permitiu definir os enquadramentos presentes no jornal.

Com o objetivo de aperfeiçoar a objetividade do processo de atribuição dos frames, foram observados, como ferramenta exploratória para a Análise de Enquadramento, os resultados da análise de clusters, desenvolvida no software NVivo a partir da similaridade de palavras das peças. O levantamento permitiu observar as semelhanças entre os editoriais a partir de uma análise léxica (a métrica de similaridade utilizada para gerar os clusters foi o coeficiente de Sørensen). Assim, textos que possuem maior grau de similaridade, baseado na ocorrência e na frequência das palavras, foram agrupados em um mesmo conjunto. Foi justamente tal agrupamento inicial dos editoriais que permitiu a proposição posterior dos frames, após leitura reiterada dos textos, observando o livro de códigos que contempla as variáveis da pesquisa. Cada editorial foi agrupado em apenas um

\footnotetext{
4 Como não há interesse em analisar outros tipos de congresso (científicos), por exemplo, textos que não mencionam uma das casas legislativas em tela foram excluídos da amostra.

5 Em alguns editoriais, porém, não foram encontrados os quatro elementos. Apesar disso, a abundância dos outros elementos e a semelhança entre os textos permite a identificação dos frames.
} 
tipo de enquadramento. O resultado da categorização de todos os editoriais nos frames encontrados pode ser observado na seção a seguir.

\section{Análise empírica dos editoriais do jornal Folha de S. Paulo}

A adequação dos enquadramentos propostos após a fase de pré-análise foi confirmada pela análise de cluster dos textos. Cada cor do dendograma abaixo significa um agrupamento entre textos similares entre si - e cada elemento presente na ponta dos ramos é um editorial. Alguns grupos possuem mais elementos que outros justamente porque a similaridade entre os textos não é distribuída de maneira uniforme. Os editoriais que estão em agrupamentos mais próximos entre si na figura 1 guardam mais similaridades.

É importante observar que há dois grandes ramos no dendograma, que se dividem em ramos menores. O primeiro deles trata de questões mais próximas ao jogo político, enquanto o segundo possui uma ênfase dividida entre questões sociais e questões econômicas. 
Figura 1 - Análise de cluster por similaridade de palavras ${ }^{6}$

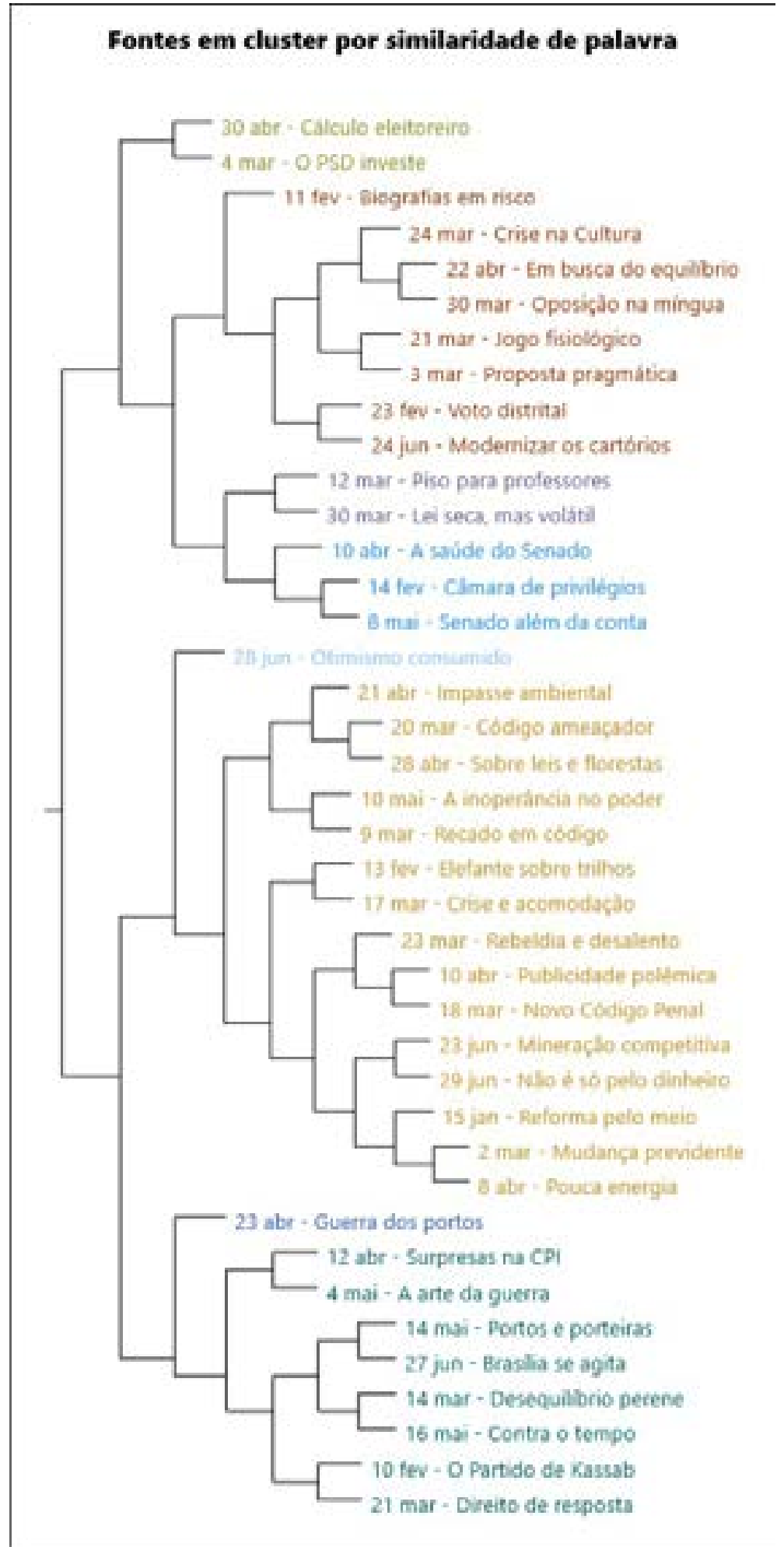

Fonte: Os autores.

6 A análise de clusters é uma técnica exploratória que permite visualizar padrões ao agrupar textos que compartilham palavras similares (NVIVO, 2017). 
No gráfico 1, logo abaixo, é possível observar que o frame que mais se repete nos textos da Folha de São Paulo é "Relações conflituosas entre Congresso e outros Poderes", estando presente em onze editoriais da amostra (27,5\% do total). Em seguida, "Fluxo do processo legislativo" é composto por dez peças (25\%). "Providências necessárias para a economia brasileira e medidas que devem ser tomadas" aparece em seis textos (15\%). Os enquadramentos "Custo do Parlamento e do Estado brasileiro", "Liberdade de expressão como um direito inquestionável" e a categoria "Outros" foram verificados em três editoriais cada um (7,5\%). Dois frames aparecem em dois textos cada (5\%). São eles: “Escândalos políticos" e "Respostas às manifestações".

Gráfico 1 - Enquadramentos identificados nos editoriais da Folha de São Paulo

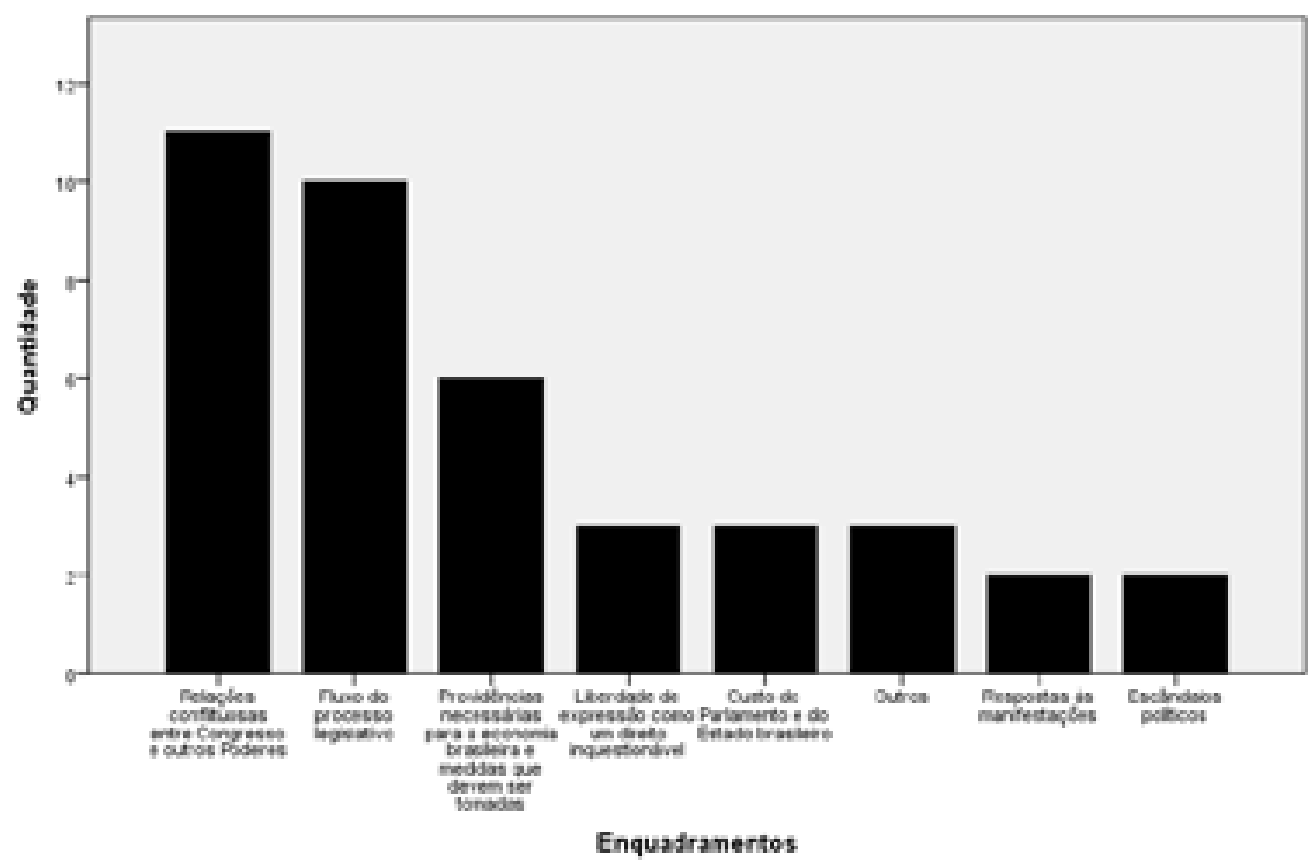

Fonte: Os autores.

A seguir, o artigo passa a discutir o teor dos enquadramentos identificados nos editoriais a partir da ilustração de trechos que permitem compreender os sentidos das imagens elaboradas pela FSP. 


\section{Análise do enquadramento 1: "Relações conflituosas entre} Congresso e outros Poderes"

O frame em questão é composto por nove editoriais. No texto "Reforma pelo meio", publicado em 15 de janeiro de 2011, a FSP critica o fato de a então presidente Dilma Rousseff não ter encaminhado ao Legislativo propostas de reformas em diversas áreas. $\mathrm{O}$ jornal acredita serem promissoras, no entanto, as mudanças propostas no sistema tributário. Por serem pontuais, as alterações exigiriam "menos negociações e negociatas no Congresso" (REFORMA..., 2011).

Percebe-se, desde os primeiros editoriais que integram o corpus, uma postura refratária ao Poder Legislativo Federal. Por exemplo, o editorial "Recado em código", de 9 de março de 2012, aborda as pressões que a base aliada exerceu sobre a então presidente em votações no Congresso, classificando a derrota sofrida pelo governo - no caso, a negativa em aceitar a indicação de Dilma para a Agência Nacional de Transportes Terrestres - como "escaramuça da base fisiológica" (RECADO..., 2012). O jornal acredita que o comportamento dos parlamentares interessa "à turma do toma lá dá cá". Para o periódico, "O golpe do Senado constitui o segundo ato da coreografada revolta do PMDB e de sócios menores do poder, após um cômico manifesto contra a hegemonia do PT no governo" (RECADO..., 2012).

Já o editorial "Desequilíbrio perene", de 14 de março de 2012, aborda conflitos do Legislativo com o Judiciário. Tratando da decisão do STF de declarar inconstitucional a medida provisória que cria o Instituto Chico Mendes, o periódico defende que o Supremo estava procurando sanar uma afronta à Constituição causada pelo Congresso. "Não é ocioso lembrar que a iniciativa de legislar cabe ao... Legislativo. No Brasil, onde o equilíbrio entre Poderes é ficção, ela costuma ser usurpada pelo Executivo" (DESEQUILÍBRIO..., 2012). Diante da situação, o periódico considera necessária a intervenção do Supremo, a fim de reequilibrar os Poderes.

Os desentendimentos entre governo e base continuam em pauta no editorial "Crise e acomodação", de 17 de março de 2012. A FSP acredita que a crise da qual se fala à época está ligada às disputas de poder entre os partidos.

Generalizou-se o nome de "crise" para uma confluência de conflitos políticos que, apesar da algazarra parlamentar, parecem circunscritos ao comércio de postos de poder - mercado de onde não devem transbordar, dada a tranquilidade social e econômica no país (CRISE..., 2012).

A FSP acredita que Dilma repete o esquema de poder montado por Lula ao redistribuir postos em ministérios e estatais, ferindo interesses e abrindo disputas 
entre os integrantes da coalizão do governo. Para a Folha, a crise não passaria de uma disputa por cargos.

O clima conflituoso paralisa o Congresso, sem dúvida, e obsta a resolução de disputas de interesse mais geral. [...] O fato de que tal conflito se limite a cargos e favores é outro diminutivo da crise. Governos e parlamentos brasileiros têm de se arranjar e acabam por fazê-lo, pois não têm mais onde buscar o que cobiçam: docilidade no Congresso e feudos de poder (CRISE..., 2012).

Em "Jogo fisiológico", de 21 de março de 2012, a FSP aborda a tramitação de outro projeto de lei importante para o governo, a Lei Geral da Copa, e as dificuldades para aprová-lo no Congresso. O periódico afirma que a proposta ganhou "renovada projeção" devido às "pressões e chantagens que dominam as relações entre o governo federal e sua base parlamentar" (JOGO..., 2012).

Já em "Rebeldia e desalento", de 23 de março de 2012, merecem comentário do jornal as derrotas do governo, ocasionadas, uma vez mais, por descontentamento da base aliada. A FSP afirma, inclusive, que as pressões exercidas pelo Congresso são legítimas, mas interpreta que elas priorizam interesses particulares dos envolvidos. "Tudo seria sinal de vigor democrático, não fosse a circunstância de que movimentos dessa natureza tendem a ser aplacados não tanto pela negociação concreta em pontos doutrinários como pela distribuição de novos cargos e verbas." (REBELDIA..., 2012).

O editorial "Em busca do equilíbrio", de 22 de abril de 2012, discute o protagonismo do STF em decisões polêmicas, listando uma série de assuntos analisados pelo tribunal. Ainda que considere haver certo declínio do poder de iniciativa no Congresso, o jornal não interpreta o fato de tais decisões estarem nas mãos do STF como fragilidade institucional. "Mesmo um Congresso excepcionalmente ativo poderia ver judicialmente contestadas as suas decisões, numa sociedade democrática e complexa como a brasileira" (EM BUSCA..., 2012).

Os conflitos entre governo e base continuam em pauta no editorial "Portos e porteiras", de 14 de maio de 2013. A FSP repercute a entrevista do então líder do PMDB na Câmara, Eduardo Cunha, na qual o deputado reclama compensações do governo ao seu partido pela aliança. Para o periódico, “[...] não se tem notícia de que o PMDB trabalhe sem remuneração. Bem ao contrário, tem sido regiamente compensado pelo governo federal" (PORTOS..., 2013).

O último editorial lotado no enquadramento ora analisado é "Contra o tempo", de 16 de maio de 2013, que aborda a votação da MP dos Portos. A Folha 
menciona os benefícios liberados pelo governo aos parlamentares para garantir a aprovação do projeto, mas acredita que seria justificável, devido aos problemas dos portos brasileiros. "Sai muito caro, como de hábito, tanger o Congresso na direção necessária - ainda assim, muito mais barato que tolerar o atraso feudal dos portos nacionais. E o Congresso precisa decidir se vai ficar a favor da necessidade histórica - ou contra ela" (CONTRA..., 2013).

Pode-se afirmar que parte considerável das peças enquadradas nesta categoria trata das disputas entre o governo e a base no Congresso - sendo prática recorrente desta criar dificuldades a fim de lucrar com as necessidades do Executivo. Ressalte-se, aliás, que o Legislativo não é, deste modo, encarado pelo jornal como um Poder passivo ou refém.

\section{Análise do enquadramento 2: "Fluxo do processo legislativo"}

Dez editoriais compõem o frame "Fluxo do processo legislativo". Em comum, eles tratam do papel do Congresso quando o que está em jogo é o fluxo do processo decisório, ainda que se referindo a temáticas distintas.

Em "Voto distrital", de 23 de fevereiro de 2011, a FSP defende a adoção de tal tipo de sistema para eleições proporcionais - consolidando oportunidade adicional para criticar os agentes do Legislativo.

\footnotetext{
São diversas as causas dessas mazelas - da tradição patrimonialista à ainda escassa experiência democrática brasileira. Entre elas, pode-se citar também a contribuição do sistema eleitoral. Pelo modelo vigente, deputados disputam de forma individual o escrutínio dos eleitores dispersos em colégios gigantescos. Uma vez eleitos, representam da maneira que lhes aprouver os interesses de seus Estados, partidos e apoiadores (VOTO..., 2011).
}

A FSP também apresenta as medidas que entende como melhorias para a legislação trabalhista e previdenciária. O editorial "Mudança previdente", de 2 de março de 2012, discute a aprovação na Câmara do projeto que altera a previdência dos servidores públicos.

Referindo-se à discussão sobre atualização do Código Penal, o texto "Proposta pragmática", de 3 de março de 2012, propõe a realização de uma consulta à população para decidir sobre a descriminalização do aborto. Nele critica o caminho adotado para tratar do tema adotado pela comissão responsável pela reforma do Código. "A comissão do Senado para a reforma do Código Penal parece ter 
tomado um caminho tortuoso para tratar do tema. Propôs que o aborto deixe de ser crime em outras situações, além das já previstas na lei." (PROPOSTA..., 2012).

O Código Penal volta à pauta no dia 18 de março de 2012, no editorial "Novo Código Penal". Nele, a FSP avalia que a reforma conduzida pela Câmara estaria na direção correta ao voltar-se para valorizar penas alternativas e para a punição de crimes violentos e corrupção. Todavia, "[...] ao pôr de lado temas como aborto ou eutanásia, a comissão reforça a tendência preocupante de parlamentares a se omitirem em temas polêmicos". (NOVO..., 2012)

Em "Impasse ambiental", de 21 de abril de 2012, a FSP critica as alterações propostas na matéria relativa ao Código Florestal pelo relator do texto na Câmara, deputado Paulo Piau (PMDB). O editorial "Sobre leis e florestas", de 28 de abril de 2012, repercute a aprovação do Código Florestal. Segundo a FSP, o texto aprovado pela Câmara teria consequências para o jogo político, e o periódico dá a entender que a importância de uma norma mais adequada seria mais relevante que as disputas partidárias. "A bancada ruralista da Câmara, liderada pelo sempre governista e inconfiável PMDB, acredita ter infligido nova derrota política à presidente Dilma Rousseff. Na prática, deu um golpe em favor do atraso" (SOBRE..., 2012). Na visão do jornal, o novo Código Florestal "nasce velho e relega a proteção do ambiente brasileiro. Não foi desta vez, ainda, que o país conseguiu decidir o quanto de patrimônio natural e legal quer deixar para futuras gerações" (SOBRE..., 2012).

Nos editoriais acima, a FSP sugeriu alterações em regras de diversas áreas frequentemente, criticando as decisões tomadas pelo Congresso. O periódico procura encarnar uma posição de defesa do interesse público, considerando-se apto a elaborar julgamentos morais ou a criticar a postura de representantes eleitos.

\section{Análise do enquadramento 3: "Providências necessárias para a economia brasileira e medidas que devem ser tomadas"}

O frame analisado é composto por seis peças. Ao contrário do enquadramento anterior, a ênfase temática dos editoriais aqui classificados se dá menos no funcionamento interno das Casas Legislativas e mais no papel que senadores e deputados têm no que se refere ao crescimento econômico do país. No editorial "Elefante sobre trilhos", de 13 de fevereiro de 2011, por exemplo, discute-se o projeto de construir um trem-bala entre São Paulo e Rio de Janeiro. O jornal vê semelhanças da obra com os "elefantes brancos do desenvolvimentismo irresponsável do final do regime militar" (ELEFANTE..., 2011). 
O texto "Guerra dos portos" é de 23 de abril de 2012. Trata-se de crítica aos incentivos fiscais concedidos a produtos importados. O jornal aponta a importância do projeto que poderia ser votado pelo Senado, encerrando "a disputa entre portos brasileiros" (GUERRA..., 2012). Para o periódico, "O projeto em debate no Senado pode ensejar uma ação mais coordenada e racional" (GUERRA..., 2012) entre os estados. O tom, neste caso, é menos de crítica e mais de realce quanto ao papel do parlamento.

Os incentivos fiscais também são tema do editorial "A arte da guerra", de 4 de maio de 2013. A FSP aborda a reforma no ICMS, cujo trâmite teria sido apressado devido à possibilidade de um apagão legal, pois as manobras com o imposto estavam sendo invalidadas pelo Supremo Tribunal Federal (STF). A Folha acredita, porém, que a proposta está sob ameaça, o que poderia agravar a chamada guerra fiscal.

Em "Mineração competitiva”, de 23 de junho de 2013, a FSP aborda o Código de Mineração enviado pelo governo ao Congresso, que "pretende iniciar a necessária modernização desse segmento da economia" (MINERAÇÃO..., 2013). O periódico explica minúcias do projeto e o quanto a arrecadação de impostos tende a aumentar com sua aprovação, surpreendendo-se com o fato de o governo ter "demorado tanto para enviar a proposta ao Congresso" (MINERAÇÃO..., 2013). Percebe-se, no caso, um comportamento comum da FSP nos editoriais analisados ao longo do período: se, por um lado, o jornal critica Dilma Rousseff (como no caso da construção do trem-bala, apresentado cima), por outro, a então presidente é elogiada por atuar como protagonista na modernização da economia. Mais constante, porém, é a crítica aos agentes do Poder Legislativo.

\section{Análise do enquadramento 4: "Liberdade de expressão como um direito inquestionável"}

O frame em tela traz três editoriais. O primeiro é "Biografias em risco", de 11 de fevereiro de 2011, tratando do projeto de lei permitindo a publicação de biografias de pessoas de notoriedade pública sem a autorização delas ou de seus familiares. A Folha de S. Paulo considera "elogiável" a iniciativa do ministro da Justiça, José Eduardo Cardozo, de alterar a legislação. No caso, o papel do Congresso é secundário em relação ao Executivo, cabendo àquele apenas a expectativa de acatar a proposta.

Em "Direito de resposta", de 21 de março de 2012, a FSP aborda o projeto regulamentando o direito de resposta no Brasil, aprovado pelo Senado. O jornal defende a necessidade da iniciativa, mas acredita que "[... a Câmara dos Deputados 
precisará aprimorar o texto legal para sanar problemas que o afastam de seu objetivo maior" (DIREITO..., 2012). Embora julgue que o direito de resposta precisa ser regulamentado, a Folha coloca a liberdade de expressão como um direito superior, que não pode ser ameaçado. No caso, fica evidente o interesse do periódico na questão, tendo em vista que a medida tem potencial para afetar diretamente aquelas atividades exercidas pela empresa jornalística. Ao mesmo tempo, o editorial em tela reivindica a postura de defensor de um interesse público no sentido amplo (a liberdade de expressão), com a intenção chamar para si a responsabilidade por zelar o que considera uma propriedade das democracias.

No editorial "Publicidade polêmica", de 10 de abril de 2012, o jornal debate o projeto de lei que propunha vetar a propaganda dirigida ao público infantil. A FSP defende que o melhor caminho seria a autorregulamentação, proposta pelo Conselho Nacional de Autorregulamentação Publicitária (Conar), e não uma proibição proveniente do Congresso, posicionando-se, assim, quanto aos limites que considera plausíveis acerca da atuação do Estado.

\section{Análise do enquadramento 5: "Custo do Parlamento e do Estado brasileiro"}

Três textos envolvem o frame em questão. O primeiro editorial é "Câmara de privilégios", de 14 de fevereiro de 2011. Nele, a FSP critica não só o aumento nos salários dos deputados federais, mas também os gastos da Câmara de Vereadores de São Paulo. O jornal questiona, ademais, as verbas de gabinete concedidas aos parlamentares. "Assim como no Congresso, o custo de cada integrante da Câmara para o contribuinte reside sobretudo nos gastos de gabinete" (CÂMARA..., 2011).

O editorial "A saúde do Senado", de 10 de abril de 2012, aborda os gastos nos serviços médicos da Casa. A saúde... (2012) A FSP (A SAÚDE..., 2012) menciona reportagem feita pela TV Folha sobre os custos para manter "uma unidade de saúde pouco utilizada por parlamentares, servidores e seus dependentes".

Se do ponto de vista prático o serviço médico do Senado é um esbanjamento, pelo aspecto simbólico trata-se de um acinte: enquanto suas salas ficam vazias, e seus profissionais, ociosos, pacientes enfrentam filas em uma UPA (Unidade de Pronto Atendimento) do governo do Distrito Federal.

Em "Senado além da conta", de 8 de maio de 2013, o jornal aborda outros gastos desnecessários da Casa, como auxiliares de check-in nos aeroportos, sala 
especial para aguardar o voo ou cinco passagens aéreas mensais de ida e volta para o estado de origem dos parlamentares. No caso, a crítica é endereçada não somente à Casa, mas personalizada na figura do então presidente do Congresso.

Vê-se que não vai longe a propalada disposição de Renan Calheiros (PMDB-AL) para reduzir as despesas da Casa. Eleito presidente do Senado sob protesto da opinião pública, ele anunciou cortes anuais de $R \$ 262$ milhões (num orçamento de $R \$ 3,4$ bilhões). Mas a tesoura preservou os congressistas (SENADO..., 2013).

Novamente, o tom adversário caracteriza a cobertura editorial, construindo uma imagem pública negativa do parlamento.

\section{Análise do enquadramento 6: "Outros"}

Três editoriais que integram a amostra não trouxeram elementos suficientes para serem agrupados nos enquadramentos existentes. A fim de evitar criar um enquadramento exclusivo para cada texto, propôs-se a criação da categoria "Outros".

O editorial "Lei seca, mas volátil", de 30 de março de 2012, discute as limitações da Lei Seca brasileira. A FSP afirma que a decisão do STJ de condicionar a punição ao teste do bafômetro é correta, mas que isso diminui o poder da fiscalização, pois o condutor pode recusar-se a fazer o teste. Para o periódico, o interesse dos parlamentares seria reagir a uma exigência da população, mas sem preocupação com a real eficácia da lei.

Percebe-se logo que os parlamentares estão mais preocupados em
parecer rigorosos do que em redigir uma norma exequível. Melhor
fariam se se limitassem a reintroduzir na lei a possibilidade da prova
testemunhal para configurar o crime, mas somente para aqueles ca-
sos em que a embriaguez do motorista produza vítimas (LEI..., 2012).

Outro editorial a ser analisado neste enquadramento se chama "Modernizar os cartórios", de 24 de junho de 2013. A FSP se opõe à PEC dos Cartórios, cuja proposta era manter à frente do serviço aqueles que sustentarem por cinco anos ininterruptos a titularidade do órgão, mesmo sem concurso. "Pródigo em decisões contra o interesse público, o Congresso se prepara para reexaminar uma proposta de emenda constitucional de 2005 para dar titularidade a donos de cartórios que não cumprem a exigência de concurso público" (MODERNIZAR..., 
2013). Para o periódico, seria necessária uma reforma nos serviços notariais, aumentando a concorrência e diminuindo a burocracia das exigências documentais dos três níveis de governo.

\section{Análise do enquadramento 7: Respostas às manifestações}

Em "Respostas às manifestações", estão agrupadas duas peças. O editorial "Brasília se agita", de 27 de junho de 2013, aborda as respostas de diversas instituições às manifestações de rua que marcam aquele mês. A FSP inicia o texto afirmando que até o STF foi pautado pelo "clamor das ruas" ao condenar o então deputado federal Natan Donadon à prisão.

O periódico demonstra maior surpresa, porém, em relação às reações do Congresso Nacional, o que representaria o susto causado pelas manifestações. "Foi o Congresso Nacional, no entanto, que se excedeu na repentina demonstração de apreço pela opinião pública. Como o Legislativo tem sido o Poder mais refratário a ela, fica patente o quanto Brasília tremeu diante dos protestos" (BRASÍLIA..., 2013). Todavia, nem só de iniciativas positivas seriam compostas as ações do Congresso e do Executivo, avalia o jornal: "Algumas proposições, contudo, sucumbem ao populismo barato. Encaixam-se perfeitamente nessa rubrica tornar a corrupção um crime hediondo e criar o passe livre para estudantes" (BRASÍLIA..., 2013).

O último editorial deste enquadramento é "Não é só pelo dinheiro", publicado em 29 de junho de 2013, que trata da quantidade de verbas prometidas para as áreas de saúde e de educação após as manifestações acima mencionadas. A FSP (NÃO..., 2013) critica a proposta de repassar 10\% do valor do PIB em educação, pois, segundo a publicação, não haveria verba suficiente para cobrir os dispêndios. "Como de hábito, o poder público se preocupa mais com o aumento de verbas do que com mecanismos para tornar seu uso mais eficiente". Assim, ao mesmo tempo em que vê com simpatia as manifestações e os efeitos causados por elas junto aos agentes políticos, a FSP preocupa-se com as consequências das propostas apresentadas.

\section{Análise do enquadramento 8: Escândalos políticos}

Dois editoriais trazem o frame "Escândalos políticos". Em "Oposição na míngua", de 30 de março de 2012, está em pauta o envolvimento do ex-senador Demóstenes Torres com Carlos Cachoeira, então acusado de contravenção. A FSP recorda a trajetória do político goiano, que tinha papel importante como 
oposição ao governo. "Caiu-lhe bem o figurino de liderança revigoradora e aguerrida, que parecia trazer à fragilizada oposição algum alento. Ao que tudo indica, os velhos vícios da política brasileira se revelaram mais fortes que a promessa de renovação" (OPOSIÇÃO..., 2012). O periódico ainda dedica o editorial a criticar a oposição brasileira, que faria o inverso do esperado, a saber: vigiar o poder e constituir uma alternativa ao governo vigente. Essa, inclusive, é uma das poucas menções negativas que o jornal faz à oposição.

O segundo editorial é "Surpresas na CPI", de 12 de abril de 2012. Trata da instauração da CPI do Cachoeira, sucedendo um período de acomodação entre Legislativo e Executivo que vinha desde o segundo mandato de Lula.

O novo cenário aguçou o apetite petista por retribuir na mesma moeda as investidas que o partido sofreu anos atrás. Não é o caso de mera vingança, contudo; há uma dose de cálculo na adesão da cúpula do PT à CPI. Ela proveria um anestésico para a reabertura das feridas do mensalão no Supremo Tribunal Federal (SURPRESAS..., 2012).

Para a FSP, as direções de Câmara e Senado se esforçam para contar com a capacidade de controlar as investigações para permitir a instalação da comissão. A esperança do jornal parece ser, portanto, justamente os rumos inesperados que a investigação pode tomar. "Nunca se sabe, contudo, como as CPIs terminam, segundo reza o ditado brasiliense. O Congresso, mesmo que não queira, ainda pode surpreender a opinião pública" (SURPRESAS..., 2012).

A próxima seção se dedica a refletir sobre os achados da investigação considerando a literatura da área. Verifica-se em que medidas as hipóteses foram ou não confirmadas.

\section{Discussão dos achados e conclusões}

Os frames encontrados, bem como o exame detalhado dos textos que os integram, apontam para a confirmação da hipótese 1: os editoriais adotam um tom negativo em relação ao Congresso Nacional, uma vez que enquadram o Legislativo Federal e seus integrantes como atores continuamente envolvidos em barganhas, irregularidades e escândalos. Ressalte-se que tal caracterização não está atrelada a um período específico (com profusão de escândalos, por exemplo) que pudesse enviesar a cobertura. A FSP repreende a atuação da Câmara e do Senado, seja pela morosidade, seja pelo teor dos projetos aprovados no Congresso, ou por desconsiderar pautas e perspectivas julgadas fundamentais pelo periódico. Assim, 
durante os meses distribuídos ao longo dos três anos que integram a amostra, a avaliação negativa do Poder Legislativo Federal é persistente.

É justamente tal abordagem que permite comprovar a hipótese 2: ao tratar do Congresso em seus editoriais, a FSP procura construir sua própria imagem como defensora do interesse público. Tal comportamento se apresenta, frequentemente, por meio de editoriais que ressaltam o contraste entre a empresa jornalística, de um lado, e as instituições do campo político, de outro, confirme ilustrado em diversos trechos que integram a seção anterior deste artigo. Em outras palavras, a imagem da FSP enquanto instituição defensora daquilo que considera sendo de interesse público é construída à medida que o periódico elabora uma ideia negativa acerca de determinados agentes da política. Destaque-se, ademais, que o processo de se posicionar como representante do interesse público também implica a defesa, por parte da Folha, de um conjunto de agendas e demandas que os editoriais do jornal vendem como se fossem de benefício geral, evitando apresentá-las como particulares. Percebe-se, aqui, certo esforço da publicação para desvincular o editorial daquela noção de que tal texto apenas serviria para atender, de forma egoísta, à perspectiva dos controladores da empresa jornalística.

Conforme pode ser verificado a seguir, os dados conferem a oportunidade de debater outros aspectos que transcendem a formulação inicial das duas hipóteses.

A priorização das disputas com o Executivo, conforme apontado pelo frame mais recorrente no material analisado, reafirma os achados da pesquisa de Azevedo (2005), na qual o autor analisa a cobertura sobre o Senado nos editoriais do mesmo jornal aqui investigado. Assim como naquele caso, percebe-se a centralidade do Executivo como articulador principal do jogo político nacional. Mesmo com as palavras-chave remetendo-se a Congresso, Senado e Câmara, os conflitos envolvendo parlamento e governo são o enquadramento dominante - sendo que a então chefe do Executivo dispõe de visibilidade considerável na cobertura, em sintonia com o padrão encontrado em outras investigações que se debruçam sobre coberturas jornalísticas em regimes presidencialistas (COOK, 1989; AZEVEDO, 2005; MONT'ALVERNE, 2017).

Por um lado, pode-se entender o endereçamento ao Executivo como natural, uma vez que os poderes se envolvem em constantes negociações (COUTO; ABRUCIO, 2003; LIMONGI, 2006; MASSILLI, 2013)interagindo por meio de acordos, negocia \uooe7 \uoof5es, coaliz \uoof5es e conflitos. As institui \uooe7 $\backslash$ uoof5es \u2013 tanto formais como informais \u2013 s\uooezo consideradas funda-mentalmente param\uooegtricas \uooeos a \uooe7 \uoof5es em curso, demarcando o campo de possibilidades dispon\uooedveis aos atores. Quanto 
$\backslash$ uooeos agendas de pol \uooedticas p\uoofablicas, detemos nosso foco princi-palmente sobre a agenda de pol\uooedtica econ\uoof4mica e as reformas constitu-cionais a ela relacionadas. Centramos o foco nesses temas, uma vez que delimitam possibilidades \uooeos demais agendas e, conseq\uoofcentemente, condi-cionam com maior for \uooe7a as coaliz \uoof5es poss \uooedveis \u2013 sobretudo aquelas envol-vendo as organiza\uooe $>\backslash u o o f 5 e s$ partid \uooerrias. Elementos do jogo pol \uooedtico $1 \mathrm{Na}$ busca de seus objetivos, ou seja, da consecu \uooe7\uooezo de suas agendas, os atores levam em considera\uooe7 $\backslash$ uooe3o quatro elementos: 1. Isto faz com que a caracterização e a construção de imagem de um Poder estejam sempre atreladas àquela de seu par. Por outro lado, a FSP avalia que, não obstante a capacidade da Presidência de editar medidas provisórias, nomear apadrinhados ou liberar verbas, o Legislativo não adota uma atitude necessariamente passiva.

Há indícios que permitem confirmar o argumento de Albuquerque (2000) de que existem diferentes lógicas de cobertura quando o Jornalismo lida com diferentes Poderes. No caso da postura em relação ao Executivo, a FSP segue a lógica da autoridade, enquanto, ao se referir ao Legislativo, obedece à lógica da política. "No primeiro caso a ênfase recai principalmente sobre questões relativas ao interesse da Nação como um todo [...]; no segundo, têm-se em vista os interesses particulares dos (ou representados pelos) agentes envolvidos, e do processo de barganha que se estabelece em torno deles".

Deve-se notar, porém, uma singularidade a partir do que foi aqui apresentado: as disputas entre governo e aliados no Congresso despertam mais atenção da cobertura editorial do que as discordâncias entre governo e oposição. Em outras palavras, a avaliação predominante é a de que, mais do que a oposição, quem complicaria os interesses do Executivo seriam os próprios governistas (não obstante o número alto de lotados, em princípio, em partidos da base).

Para a FSP, as propostas de criação de Comissões Parlamentares de Inquérito (CPIs) ou a recusa de indicados por Dilma para assumir cargos em agências do governo não seriam sinais de compromisso do Congresso com apuração de irregularidades ou preocupação com a competência dos gestores; consistem em formas de pressionar o Executivo a atender a demandas (muitas vezes pessoais) dos legisladores.

No final das contas, a independência republicana entre os Poderes e a necessidade de concerto mínimo entre os diferentes agentes do campo político para que os problemas do país sejam enfrentados acabam interpretadas pelos editoriais como mero pano de fundo que alimenta o poder de barganha daqueles que priorizam interesses particularistas. Em outras palavras, elementos que caracterizam 
a configuração institucional da democracia brasileira e que foram pensados para garantir um sistema de checks and balances (MANIN, 1994; ANASTASIA; NUNES, 2006) seriam desvirtuados, na perspectiva do periódico em questão, para pressionar os tomadores de decisão a agir de acordo com os interesses particularistas.

Ressalte-se que o Legislativo também é apresentado de forma negativa em relação ao Judiciário, que seria responsável por resolver problemas criados devido às negociações entre Congresso e Executivo. Assim, mesmo intervenções do STF na atuação do Legislativo não são vistas de forma problemática, mas como instrumentos para adequá-la às regras.

O jornal expressa o afastamento do Poder Legislativo daquelas que seriam as reais demandas da sociedade (mesmo que não mencionem um conjunto específico de demandas, os editoriais, de forma recorrente, apontam como o dinheiro do contribuinte deveria ser gasto; ou defendem pautas a exemplo do voto distrital). Este tom de cobertura implica, assim, parte da estratégia por meio da qual a empresa se mostra independente e representante do público, na medida em que critica diversos lados - não obstante a possibilidade de alinhamentos político-ideológicos (temporários ou não).

Em alguma medida, tal postura isso se relaciona com o papel que a FSP atribui a si mesma, por exemplo, em seu Manual de Redação, quando se considera portadora de um mandato conferido pelo leitor. Nesse sentido, o jornal atribui a si próprio "um papel metapolítico, de principal intérprete do interesse nacional, por cima das instituições políticas representativas" (ALBUQUERQUE; HOLZBACH, 2008, p. 169), de modo que "paira" sobre outras instituições do país, apontando problemas e soluções.

\section{Referências}

ALBUQUERQUE, A. Um outro quarto poder: jornalismo e responsabilidade política no Brasil. Contracampo, v. 4, p. 23-57, 2000.

ALBUQUERQUE, A. DE; HOLZBACH, A. D. Metamorfoses do contrato representativo: jornalismo, democracia e os manuais da redação da Folha de S. Paulo. Comunicação, mídia e consumo, v. 5, n. 14, p. 149-170, 2008.

ALDÉ, A.; MENDES, G.; FIGUEIREDO, M. Tomando partido: imprensa e eleições presidenciais em 2006. Política e Sociedade, v. 6, n. 10, p. 153-172, 2007.

ANASTASIA, F.; NUNES, F. A Reforma da Representação. In: AVRITZER, L.; ANASTASIA, F. (Ed.). Reforma Política no Brasil. Belo Horizonte: UFMG, 2006. p. 17-33. 
ARMAÑANZAS, E.; NOCÍ, J. D. Periodismo y argumentación. Géneros de opinión. Universidad del País Vasco, 1996.

ARNOLD, R. D. Congress, the Press, and Political Accountability. Princeton: Princeton University, 2004.

ASSOCIAÇÃO NACIONAL DE JORNAIS. Maiores jornais do Brasil, 2017. Disponível em: http://www.anj.org.br/maiores-jornais-do-brasil. Acesso em: 5 dez. 2017.

AVRITZER, L.; ANASTASIA, F. Reforma política no Brasil. Belo Horizonte: UFMG, 2006.

AZEVEDO, F. A Grande Imprensa Brasileira: Paralelismo Político e Antipetismo (19892014). Universidade Federal de São Carlos, 2016.

AZEVEDO, F. A. Imprensa e Legislativo: os editoriais da Folha de S. Paulo sobre o Senado (2003-2004), 2005. Disponível em: http://www.compos.org.br/data/biblioteca_793. pdf. Acesso em xxx

HAIA, V. O Senado nos editoriais dos jornais paulistas (2003-2004). Opinião Pública, v. 14, n. 1, p. 173-204, 2008. https://doi.org/10.1590/S0104-62762008000100007

A ARTE da guerra. Folha de S. Paulo, São Paulo, 4 mai. 2013. Opinião, Editoriais, p. A2.

A INOPERÂNCIA no poder. Folha de S. Paulo, São Paulo, 10 maio 2013. Opinião, Editoriais, p. A2.

A SAÚDE do Senado. Folha de S. Paulo, São Paulo, 10 abr. 2012.Opinião, Editoriais, p. A2.

BARROS FILHO, C. Ética na Comunicação: de informação ao receptor. São Paulo: Moderna, 1995.

BELTRÃO, L. Jornalismo opinativo. Porto Alegre: Sulina, 1980.

BENETTI, M. Jornalismo e perspectivas de enunciação: uma abordagem metodológica. Intexto, n. 14, 2006.

BIOGRAFIAS em risco. Folha de S. Paulo, São Paulo, 11 fev. 2011. Opinião, Editoriais, p. A2. BRASÍLIA se agita. Folha de S. Paulo, São Paulo, 27 jun. 2013. Opinião, Editoriais, p. A2. CÁLCULO eleitoreiro. Folha de S. Paulo, São Paulo, 30 abr. 2012. Opinião, Editoriais, p. A2. CÂMARA de privilégios. Folha de S. Paulo, São Paulo, 14 fev. 2011. Opinião, Editoriais, p. A2.

CERVI, E. U.; MASSUCHIN, M. G. Metodologia quantitativa em pesquisas sobre cobertura jornalística: análise da eleição municipal de 2012 na Folha de S. Paulo. Famecos, Porto Alegre, v. 20, n. 3, p. 840-865, 2013. https://doi.org/10.15448/1980-3729.2013.3.13324 
CHRISTOFOLETTI, R.; LAUX, A. P. F. Confiabilidade, credibilidade e reputação: no jornalismo e na blogosfera. Intercom, v. 31, n. 1, p. 30-49, 2008.

CÓDIGO ameaçador. Folha de S. Paulo, São Paulo, 20 mar. 2012. Opinião, Editoriais, p. A2. CONTRA o tempo. Folha de S. Paulo, São Paulo, 16 maio 2013. Opinião, Editoriais, p. A2. COOK, T. E. Making laws and making News. Washington, DC: The Brookings Institution, 1989.

COOK, T. E. Governing with the news. Chicago: The University of Chicago, 2005. https://doi.org/10.7208/chicago/9780226026688.001.0001

COUTO, C. G.; ABRUCIO, F. O segundo governo FHC: coalizões, agendas e instituições. Tempo Social, v. 15, p. 269-301, 2003. https://doi.org/10.1590/S0103-20702003000200011

CRISE e acomodação. Folha de S. Paulo, São Paulo, 17 mar. 2012. Opinião, Editoriais, p. A2. CRISE na cultura. Folha de S. Paulo, São Paulo, 24 mar. 2012. Opinião, Editoriais, p. A2. DESEQUILÍBRIO perene. Folha de S. Paulo, São Paulo, 14 mar. 2012. Opinião, Editoriais, p. A2.

DE VREESE, C. H. News framing: Theory and Typology. Information Design Journal + Document Design, v. 13, n. 1, p. 51-62, 2005. https://doi.org/10.1075/idjdd.13.1.06vre

DIREITO de resposta. Folha de S. Paulo, São Paulo, 21 mar. 2012. Opinião, Editoriais, p. A2. EILDERS, C. Synchronization of Issue Agendas in News and Editorials of the Prestige Press in Germany. The International Journal of Communications Research, v. 24, n. 3 , p. 301-328, 1999. https://doi.org/10.1515/comm.1999.24.3.301

ELEFANTE sobre trilhos. Folha de S. Paulo, São Paulo, 13 fev. 2011. Opinião, Editoriais, p. A2.

EM BUSCA do equilíbrio. Folha de S. Paulo, São Paulo, 22 abr. 2012. Opinião, Editoriais, p. A2.

ENTMAN, R. M. Framing: Toward clarification of a fractured paradigm. Journal of Communication, v. 43, n. 4, p. 51-58, 1993. https://doi.org/10.1111/j.1460-2466.1993. tb01304.x

ENTMAN, R. M. Projections of power: framing news, public opinion, and U.S. foreign policy. Chicago: The University of Chicago, 2004. https://doi.org/10.7208/chicago/9780226210735.001.0001

ESSARY, E. H. Speaking of Globalization: Frame Analysis and the World Society. International Journal of Comparative Sociology, v. 48, n. 6, p. 509-526, 2007. https:// doi.org/10.1177/0020715207083341 
FERES JÚNIOR, J.; SASSARA, L. D. O. O cão que nem sempre late: o Grupo Globo e a cobertura das eleições presidenciais de 2014 e 1998. Compolítica, v. 6, n. 1, p. 30-63, 2016. https://doi.org/10.21878/compolitica.2016.6.1.94

FIGUEIREDO, A. C.; LIMONGI, F. Executivo e Legislativo na nova ordem constitucional. Rio de Janeiro: FGV, 2001.

FOLHA DE SÃO PAULO (São Paulo). Novo Manual da Redação. São Paulo: Folha da Manhã, 2015. Disponível em: http://www1.folha.uol.com.br/folha/circulo/manual_texto_e.htm. Acesso em: 9 dez. 2017.

FOLHA. Projeto Folha, 2017a. Disponível em: http://www1.folha.uol.com.br/folha/ circulo/manual_projeto_intruducao.htm. Acesso em: 9 dez. 2017

FOLHA. Projetos editoriais anteriores, 2017b. Disponível em: http://temas.folha.uol. com.br/projeto-editorial-da-folha/projetos-editoriais-anteriores/1981-a-folha-e-alguns-passos-que-e-preciso-dar.shtml. Acesso em: 12 dez. 2017.

GOMES, W. Transformações da política na era da comunicação de massa. São Paulo: Paulus, 2004.

GUAZINA, L. S. Jornalismo em busca da credibilidade: A cobertura adversária do Jornal Nacional no Escândalo do Mensalão. [S. l.]: Universidade de Brasília, 2011.

GUERRA dos portos. Folha de S. Paulo, São Paulo, 23 abr. 2012. Opinião, Editoriais, p. A2.

HALLOCK, S. M. Editorial and Opinion. Praeger: Westport, 2007.

HANGGLI, R. Key Factors in Frame Building: How Strategic Political Actors Shape News Media Coverage. American Behavioral Scientist, v. 56, n. 3, p. 300-317, 2012. https:// doi.org/10.1177/0002764211426327

IMPASSE ambiental. Folha de S. Paulo, São Paulo, 21 abr. 2012. Opinião, Editoriais, p. A2. JAMIESON, K. H.; WALDMAN, P. The press effect: Politicians, Journalists and the Stories That Shape the Political World. New York: Oxford University, 2003.

JOGO fisiológico. Folha de S. Paulo, São Paulo, 21 mar. 2012. Opinião, Editoriais, p. A2.

JORGE, V. L. A cobertura do Congresso Nacional pelos jontais brasileiros, 1985-1990. Estudos Históricos, n. 31, p. 64-82, 2003.

KIM, S.; SCHEUFELE, D.; SHANAHAN, J. Think about it this way: Attribute agenda- setting function of the press and the public's evaluation of a local issue. Journalism \& Mass Communication Quarterly, v. 79, n. 1, p. 7-25, 2002. https://doi. org/10.1177/107769900207900102

LEl seca, mas volátil. Folha de S. Paulo, São Paulo, 30 mar. 2012. Opinião, Editoriais, p. A2. 
LIMONGI, F. Presidencialismo e governo de coalizão. In: AVRITZER, L.; ANASTASIA, F. (ed.). Reforma Política no Brasil. Belo Horizonte: UFMG, 2006. p. 237-257.

LISBOA, Sílvia. Jornalismo e a credibilidade percebida pelo leitor: independência, imparcialidade, objetividade, honestidade e coerência. 2012. Dissertação (Mestrado em Comunicação) - Faculdade de Biblioteconomia e Comunicação, Universidade Federal do Rio Grande do Sul, Porto Alegre, 2012. Disponível em: https://lume.ufrgs.br/handle/10183/54507.

MANIN, B. Checks, Balances and Boundaries: the Separation of Powers in the Constitutional Debate of 1787. In: FONTANA, B. (ed.). The invention of modern Republic. Cambridge: Cambridge University, 1994. p. 60-61.

MANN, T. E.; ORNSTEIN, N. J. Congress, the press and the public. Washington: The Brookings Institution, 1994.

MATTHES, J.; KOHRING, M. The Content Analysis of Media Frames: Toward Improving Reliability and Validity. Journal of Communication, v. 58, n. 2, p. 258-279, jun. 2008. https://doi.org/10.1111/j.1460-2466.2008.00384.x

MENDONÇA, R. F.; SIMÕES, P. G. Enquadramento: Diferentes operacionalizações analíticas de um conceito. Revista Brasileira de Ciências Sociais, v. 27, n. 79, p. 187-201, 2012. https://doi.org/10.1590/S0102-69092012000200012

MIGUEL, L. F.; COUTINHO, A. D. A. A crise e suas fronteiras: oito meses de "mensalão" nos editoriais dos jornais. Opinião Pública, v. 13, n. 1, p. 97-123, jun. 2007. https://doi. org/10.1590/S0104-62762007000100004

MINERAÇÃO competitiva. Folha de S. Paulo, São Paulo, 23 jun. 2013. Opinião, Editoriais, p. A2.

MIOLA, E. Sistema deliberativo e tensões entre interesses públicos e privados: A criação da Empresa Brasil de Comunicação em debate no Congresso e na imprensa. Belo Horizonte: Universidade Federal de Minas Gerais, 2012.

MITOZO, I. B.; MOTTINHA, R. S. Eleições presidenciais 2014 e cobertura online: a interação entre comentaristas e posts nas páginas dos jornais brasileiros no Facebook. Márketing y Comunicación Política, v. 2, p. 47-65, 2016. https://doi.org/10.15304/ marco.2.2867

MODERNIZAR os cartórios. Folha de S. Paulo, São Paulo, 24 jun. 2013. Opinião, Editoriais, p. A2.

MONT'ALVERNE, C. A quem se dirigem os editoriais? Um estudo acerca de personagens e instituições mencionadas pelos jornais O Estado de S. Paulo e Folha de S. Paulo. Revista Brasileira de Ciência Política, n. 23, p. 7-34, 2017. https://doi.org/10.1590/0103335220172301 
MORAES, C. H. DE. Parcialidade alardeada: notas sobre a importância da opinião no jornalismo. In: XI COLÓQUIO DA CELACOM, 9., 2007. Anais [...] Disponível em: http:// encipecom.metodista.br/mediawiki/index.php/Parcialidade_alardeada:_notas_sobre_a_importância_da_opinião_no_jornalismo.

MUDANÇA previdente. Folha de S. Paulo, São Paulo, 2 mar. 2012. Opinião, Editoriais, p. A2.

NÃO é só pelo dinheiro. Folha de S. Paulo, São Paulo, 29 jun. 2013. Opinião, Editoriais, p. A2.

NICOLAU, J.; POWER, T. J. Instituições representativas no Brasil: balanço e reforma. Belo Horizonte: UFMG, 2007.

NOVO código penal. Folha de S. Paulo, São Paulo, 18 mar. 2012. Opinião, Editoriais, p. A2.

NVIVO. About cluster analysis, 2017. Disponível em: http://help-nv11.qsrinternational. com/desktop/concepts/about_cluster_analysis.htm. Acesso em: 9 dez. 2017.

O PARTIDO de Kassab. Folha de S. Paulo, São Paulo, 10 fev. 2011. Opinião, Editoriais, p. A2.

O PSD investe. Folha de S. Paulo, São Paulo, 4 mar. 2012. Opinião, Editoriais, p. A2.

OPOSIÇÃO na míngua. Folha de S. Paulo, São Paulo, 30 mar. 2012. Opinião, Editoriais, p. A2.

OTIMISMO consumido. Folha de S. Paulo, São Paulo, 28 jun. 2013. Opinião, Editoriais, p. A2.

PINTO, A. E. DE S. Folha. São Paulo: Publifolha, 2012.

PINTO, C. R. J. Elementos para uma análise de discurso político. Barbarói, n. 24, p. 78, 2006.

PISO para professores. Folha de S. Paulo, São Paulo, 12 mar. 2012. Opinião, Editoriais, p. A2.

PORTOS e porteiras. Folha de S. Paulo, São Paulo, 14 maio 2013. Opinião, Editoriais, p. A2. POUCA energia. Folha de S. Paulo, São Paulo, 8 abr. 2012. Opinião, Editoriais, p. A2.

POWER, T. J.; ZUCCO JR., C. O Congresso por ele mesmo: autopercepções da classe política brasileira. Belo Horizonte: UFMG, 2011.

POZOBON, R. DE O.; SCHAEFER, R. Perspectivas contemporâneas das pesquisas sobre enquadramento: uma proposta de sistematização conceitual. Fronteiras, v. 16, n. 3, p. 157-168, 2014. https://doi.org/10.4013/fem.2014.163.02

PROPOSTA pragmática. Folha de S. Paulo, São Paulo, 3 mar. 2012. Opinião, Editoriais, p. A2. PUBLICIDADE polêmica. Folha de S. Paulo, São Paulo, 10 abr. 2012. Opinião, Editoriais, p. A2. 
REBELDIA e desalento. Folha de S. Paulo, São Paulo, 23 mar. 2012. Opinião, Editoriais, p. A2.

RECADO em código. Folha de S. Paulo, São Paulo, 9 mar. 2012, Opinião, Editoriais, p. A2. REFORMA pelo meio. Folha de S. Paulo, São Paulo, 15 jan. 2011, Opinião, Editoriais, p. A2. RODRIGUES, M. R. Imprensa, Congresso e democracia. [S. I.]: Universidade de Brasília, 1997.

ROZELL, M. J. Press coverage of Congress. In: MANN, T. E.; ORNSTEIN, N. J. (ed.). Congress, the Press, and the Public. Washington: Brookings Institution, 1994. p. 59-129.

RUPAR, V. Newspapers' production of common sense: The "greenie madness" or why should we read editorials? Journalism, v. 8, n. 5, p. 591-610, 2007. https://doi. org/10.1177/1464884907081056

SCHEUFELE, D. A. Agenda- setting, priming, and framing revisted: another look at cognitive effects of political communication. Mass Communication and Society, v. 3 , n. 2\&3, p. 297-316, 2000. https://doi.org/10.1207/S15327825MCS0323_07

SELLERS, P. Cycles of spin: strategic communication in the U.S. Congress. Cambridge: Cambridge University Press, 2009. https://doi.org/10.1017/CBO9780511642289

SENADO além da conta. Folha de S. Paulo, São Paulo, 8 maio 2013. Opinião, Editoriais, p. A2.

SOBRE leis e florestas. Folha de S. Paulo, São Paulo, 28 abr. 2012. Opinião, Editoriais, p. A2.

STRÖMBÄCK, J.; NORD, L. W. Do Politicians Lead the Tango? A study of the relationship between Swedish journalists and their political sources in the context of election campaigns. European Journal of Communication, v. 21, n. 2, p. 147-164, 2006. https://doi. org/10.1177/0267323105064043

STRÖMBÄCK, J.; VAN AELST, P. Why political parties adapt to the media: Exploring the fourth dimension of mediatization. International Communication Gazette, v. 75, n. 4, p. 341-358, 1 jun. 2013. https://doi.org/10.1177/1748048513482266

SURPRESAS na CPI. Folha de S. Paulo, São Paulo, 12 abr. 2012. Opinião, Editoriais, p. A2. VAN DALEN, A. Journalism, Political. In: MAZZOLENI, G. (ed.). The International Encyclopedia of Political Communication. [S. l.]: John Wiley \& Sons, 2015. p. 1-10. https://doi.org/10.1002/9781118541555.wbiepc058

VOTO distrital. Folha de S. Paulo, São Paulo, 23 fev. 2011. Opinião, Editoriais, p. A2.

WEBER, M. H. Imagem pública. In: RUBIM, A. (ed.). Comunicação e política: conceitos e abordagens. Salvador: Edufba, 2004. p. 259-307. 


\section{Dados dos autores}

Francisco Paulo Jamil Marques: marquesjamil@gmail.com

Professor e Pesquisador da Universidade Federal do Paraná - UFPR. Pós-Doutor em Comunicação Social pela Universidade Federal de Minas Gerais - UFMG.

Endereço do autor: Universidade Federal do Paraná, Programa de Pós-Graduação em Comunicação Social. Rua Bom Jesus, 650 - Térreo, Juvevê, 80.035-010 Curitiba (PR) - Brasil

\section{Camila Mont'Alverne: camilapessoa31@gmail.com}

Doutoranda em Ciência Política pelo PPGCP-UFPR e Mestra em Comunicação pelo Programa de Pós-Graduação em Comunicação da Universidade Federal do Ceará (PPGCom-UFC).

Endereço da autora: Universidade Federal do Paraná, Programa de Pós-Graduação em Ciência Política. Rua General Carneiro, 460 - Ed. Dom Pedro I - $9^{\circ}$ andar - Sala 908, 80.060-150 - Curitiba (PR) - Brasil 